\title{
Cerebellar mutism syndrome in children with brain tumours of the posterior fossa
}

\author{
Morten Wibroe ${ }^{1,2}$, Johan Cappelen ${ }^{3}$, Charlotte Castor ${ }^{4}$, Niels Clausen ${ }^{5}$, Pernilla Grillner ${ }^{6}$, Thora Gudrunardottir ${ }^{7,8}$, \\ Ramneek Gupta ${ }^{9}$, Bengt Gustavsson ${ }^{10}$, Mats Heyman ${ }^{6}$, Stefan Holm ${ }^{6}$, Atte Karppinen ${ }^{11}$, Camilla Klausen ${ }^{12}$, \\ Tuula Lönnqvist ${ }^{13}$, René Mathiasen ${ }^{2}$, Pelle Nilsson ${ }^{14}$, Karsten Nysom², Karin Persson ${ }^{15}$, Olof Rask ${ }^{4}$, \\ Kjeld Schmiegelow ${ }^{2,16,17}$, Astrid Sehested ${ }^{2}$, Harald Thomassen $^{18}$, Ingrid Tonning-Olsson ${ }^{4}$, Barbara Zetterqvist ${ }^{19}$ \\ and Marianne Juhler ${ }^{1,16^{*}}$
}

\begin{abstract}
Background: Central nervous system tumours constitute $25 \%$ of all childhood cancers; more than half are located in the posterior fossa and surgery is usually part of therapy. One of the most disabling late effects of posterior fossa tumour surgery is the cerebellar mutism syndrome (CMS) which has been reported in up to $39 \%$ of the patients but the exact incidence is uncertain since milder cases may be unrecognized. Recovery is usually incomplete. Reported risk factors are tumour type, midline location and brainstem involvement, but the exact aetiology, surgical and other risk factors, the clinical course and strategies for prevention and treatment are yet to be determined.

Methods: This observational, prospective, multicentre study will include 500 children with posterior fossa tumours. It opened late 2014 with participation from 20 Nordic and Baltic centres. From 2016, five British centres and four Dutch centres will join with a total annual accrual of 130 patients. Three other major European centres are invited to join from 2016/17. Follow-up will run for 12 months after inclusion of the last patient. All patients are treated according to local practice. Clinical data are collected through standardized online registration at pre-determined time points pre- and postoperatively. Neurological status and speech functions are examined pre-operatively and postoperatively at 1-4 weeks, 2 and 12 months. Pre- and postoperative speech samples are recorded and analysed. Imaging will be reviewed centrally. Pathology is classified according to the 2007 WHO system. Germline DNA will be collected from all patients for associations between CMS characteristics and host genome variants including pathway profiles.

Discussion: Through prospective and detailed collection of information on 1) differences in incidence and clinical course of CMS for different patient and tumour characteristics, 2) standardized surgical data and their association with CMS, 3) diversities and results of other therapeutic interventions, and 4) the role of host genome variants, we aim to achieve a better understanding of risk factors for and the clinical course of CMS - with the ultimate goal of defining strategies for prevention and treatment of this severely disabling condition.
\end{abstract}

Trial registration: Clinicaltrials.gov: NCT02300766, date of registration: November 21, 2014.

Keywords: Cancer, Paediatric, Children, Cerebellar mutism, CMS, Brain tumour, Cerebellum, Posterior fossa syndrome, Genetics, Neurosurgery

\footnotetext{
* Correspondence: marianne.juhler@gmail.com

'Department of Neurosurgery, Rigshospitalet, Copenhagen, Denmark

${ }^{16}$ Institute of Clinical Medicine, University of Copenhagen, Copenhagen,

Denmark

Full list of author information is available at the end of the article
}

(c) The Author(s). 2017 Open Access This article is distributed under the terms of the Creative Commons Attribution 4.0 International License (http://creativecommons.org/licenses/by/4.0/), which permits unrestricted use, distribution, and reproduction in any medium, provided you give appropriate credit to the original author(s) and the source, provide a link to the Creative Commons license, and indicate if changes were made. The Creative Commons Public Domain Dedication waiver (http://creativecommons.org/publicdomain/zero/1.0/) applies to the data made available in this article, unless otherwise stated. 


\section{Background}

\section{Incidence and definition of CMS}

Central nervous system (CNS) tumours account for $25 \%$ of all cancers in children and over half of these are located in the posterior fossa [1]. For most of these patients, treatment includes surgery. Posterior fossa tumours in children are associated with high risk of chronic neurological and neurocognitive disability [2-6]. The cerebellar mutism syndrome (CMS) refers to the constellation of transient mutism, ataxia, hypotonia and irritability following surgery for cerebellar or fourth ventricle tumours in children and adolescents [7]. Although some patients may recover completely, recovery may be prolonged, and many are left with permanent disabling sequelae in the form of e.g. dysarthria, dysfluency, slowed speech rate and ataxia. Many may in addition be burdened by emotional problems and lower IQ [8-12].

The spectrum of CMS definitions varies greatly [7, 12-14], leading to differences in reported incidence and uncertainties about recovery. Incidence figures thus range from $8 \%$ $[15,16]$ to $32 \%$ [17] in children with any kind of cerebellar tumour when a variety of definitions are used, compared to $24 \%$ [12] to $39 \%$ [18] in patients with medulloblastomas using a more precise CMS definition. A recent study of 148 children with cerebellar tumours found that the overall incidence of the broader Posterior Fossa Syndrome was 28\%, subdivided by tumour pathology into $40 \%$ for medulloblastoma, $16 \%$ for astrocytoma and $20 \%$ for ependymoma [19]. The CMS definition created by the Neurology Committee of the Children's Cancer Group in USA in 1993 is currently the only one associated with a specific scoring scale [12] and is used in this project.

\section{Risk factors and prevention}

Cerebellar mutism is thought to be caused by bilateral disturbance of the dentate nuclei and/or their efferents $[16,20-24]$. Ataxia and irritability together with other cognitive, affective and motor symptoms that are frequently observed in CMS patients are caused by damage to various parts of the cerebellum and cerebello-cerebral pathways passing through the brainstem [25-28]. This can result in secondary diaschisis of supratentorial brain areas due to lack of excitatory input from cerebellum [29-31].

Known risk factors are brainstem involvement by the tumour, midline location and tumour type; thus the incidence in children with medulloblastoma is two to three times higher than for astrocytoma or ependymoma but the biological mechanisms behind these associations are uncertain [12, 19, 22, 32-35]. Recently proposed risk factors include brainstem compression by the tumour, pre-operative language impairment, low socioeconomic level of the families and left-handedness [24, 36-38]; however, these remain to be verified on large patient cohorts. Tumour size, neurosurgical techniques and approaches, radical resection and younger age at diagnosis are uncertain risk factors, as previous studies have been inconclusive [12, 23, 32-35, 39, 40]. Gender, hydrocephalus, post-operative central nervous system infections, type of neurosurgeon (adult/paediatric), and oedema/swelling of the cerebellum have not been significantly correlated to CMS and are considered unlikely risk factors [12, 16, 34, 35, 41, 42].

In traumatic brain injury common host genomic variants are related to the severity of symptoms and degree of recovery [43-45]. Similar associations are likely for surgical brain injury, but such studies have not been performed for CMS.

\section{Non-surgical treatment}

Supportive speech and rehabilitation therapy is often offered to patients with CMS, but the benefit hereof has not been demonstrated. No publications exist on systematic approaches to pharmacological neuroprotection, and pharmacological interventions are only sporadically reported in the literature [46-50]. Glucocorticosteroids are routinely given to most patients pre-, intra- and postoperatively to reduce inflammation and edema [51] [52], but there is no consensus recommendation and the impact on the clinical course of CMS is undetermined.

\section{Aims}

The study focuses on the risk factors for development and severity of CMS including surgery (approaches, techniques and tissue and vascular damage, re-operation) and host genome variants. The aims of this study are thus to describe differences in incidence, severity and clinical course of CMS related to:

1. Clinical factors: gender, age, handedness, speech, language and neuropsychological abilities before and after surgery.

2. Tumour factors: histological tumour type and tumour location

3. Surgical factors: Surgical strategy and surgical trauma including access routes, removal technique, tissue and vascular injury, bleeding and primary surgery vs. re-operation

4. Non-surgical interventions: glucocorticosteroids, other symptomatic medication and chemo- and radiotherapy

5. Host genome variants

\section{Methods/design \\ Design}

This open observational study is registered at Clinicaltrials. gov (file NCT02300766) and EANS (http://www.sbns.or g.uk/index.php/research/eu-multi-centre-trials). All children younger than 18 years with a tumour in the posterior fossa 
requiring surgery or open biopsy at one of the participating centres will be included following informed consent. Patients who have received surgery, chemotherapy and/or radiotherapy previously are also eligible. The study will run for five years with a targeted sample size of 500 patients. It opened late 2014 with participation from 20 Nordic and Baltic centres. From 2016, five British centres and four Dutch centres will join leading to an expected annual accrual of 130 patients. Three other major European centres are invited to join from 2016/17. The target of 500 patients is expected to be reached in 2018. Patients will be followed for 12 months after inclusion of the last patient, and the study will thus be completed during 2019.The participating centres provide surgery and supportive care according to local practice and register all study information in an online database developed specifically for this study. Consensus concerning the study aims, study design and data registration was achieved at three international planning meetings among the initiating centres during 2013. The annual enrolment from each country will be compared to the number of registered patients in the national cancer registries to document the inclusion rate and representativeness.

\section{Primary endpoint}

The primary endpoint is incidence and severity of CMS. Symptoms and severity are scored according to the CMS survey published by Robertsons et al. [12]. Our main focus is the impact of different surgical tumour approaches. We hypothesize that 1) minimally traumatic techniques and 2) sparing the dentate nuclei and their efferents will be associated with a $50 \%$ reduced risk of CMS when compared to more invasive tumour removal approaches. Furthermore, we hypothesize that the risk of developing CMS is higher after re-operation(s) compared to primary surgery.

\section{Secondary endpoint}

The secondary endpoint is incidence of "reduced speech output" defined as "severely reduced speech production limited to single words or short sentences which can only be elicited after vigorous stimulation" [19]. The risk of reduced speech output will be related to different surgical approaches with the underlying hypothesis that damage to the dentate nuclei and/or their efferents increases the risk.

Furthermore, we want to explore the following:

\section{Genetics}

We will analyse the role of host genome variants on development, severity and recovery from CMS by carrying out broad genetic pathway profiling of all study participants using both non-CMS cases from the study cohort and non-CNS tumour patients as controls. Genotyping will use single nucleotide polymorphism (SNP) exome enriched arrays (e.g. Illumina Omni2.5-exome platform). We will apply agnostic genome-wide association studies (GWAS) as well as more complex pathway analyses. Thus, we will interrogate combined effects of multiple SNPs acting in the same pathways or protein-protein interaction complexes using our validated non-linear machine learning algorithm (artificial neural networks approach) [53, 54], which allows testing of a large range of pathways from various databases. This approach will yield hypotheses easier to test across cohorts and also provide mechanistic insights. We hypothesize that host genome variants explain at least $50 \%$ of the variation in incidence of CMS and at least $40 \%$ of the variation in severity, duration and level of recovery from the CMS.

\section{Other non-surgical treatments including glucocorticosteroids}

The possible effects of chemo- and radiotherapy on recovery from CMS will be investigated. We hypothesize that chemo- and radiotherapy delay recovery from CMS. For descriptive documentation purposes we also ask for information on medications given specifically to treat the symptoms of CMS.

We hypothesize that glucocorticosteroids 1) given preoperatively protect against CMS due to reduced oedema; 2) given intraoperatively increase the risk of CMS due to worsening of acute neurological injury by hyperglycaemia; 3) given postoperatively negatively affect the course of CMS as earlier studies have shown a negative effect of glucocorticosteroids on the outcome of traumatic brain injury $[55,56]$. It may be expected that most patients receive glucocorticosteroids at all 3 time points which would make it difficult to assess added positive and negative effect in the same patients.

\section{Tumour type}

The incidence of the CMS will be correlated to tumour histology using the 2007 WHO classification. We hypothesize that the risk of CMS is highest among patients with medulloblastoma. With increasing focus on subtyping of medulloblastoma [57] this additional classification may later be added to the risk factor analysis.

\section{Neuroradiology}

Tumour location, enhancement pattern, invasiveness and growth velocity may affect the risk and severity of CMS $[12,18,58]$. Accordingly, we hypothesize that a statistical risk of CMS may be predicted by defining specific neuroradiological features [59-61]. Likewise, postoperative neuroradiological features could give prognostic information about probable degree of recovery. 


\section{Handedness}

We will determine whether the risk of the CMS varies according to handedness. We hypothesize that the risk of CMS is increased in left-handed patients, and possibly even more so in patients with medulloblastoma [24].

\section{Language and speech}

Our hypothesis that preoperative speech and language impairment increases the risk of postoperative speech and language deficits will be explored by recording pre- and postoperative speech (e.g. articulation, prosodic features and voice) and language (e.g. word finding difficulties, fluency and narrative ability) statuses and relating these to incidence and course of CMS. All speech recordings will be analysed nationally by speech therapists.

\section{Registration of data}

The following data will be registered at five time points by online standard registration forms:

\section{Preoperatively}

Hospital, country, patient related variables such as date of birth, handedness, comorbidities, bilingualism, gender and date of diagnosis, medical history and preoperative neurological status. A speech and language test will be performed and recorded. If the patient is younger than two years a bedside assessment of speech will be performed instead of a formalized test. A two millilitre blood sample for genetic analysis will be collected.

\section{Postoperatively within 72 of surgery}

Surgery related variables such as date, patient position during surgery, surgical approach, tumour removal method (én bloc, piecemeal or ultrasonic aspiration), duration and course of operation, damage to non-tumour tissue, complications, technology employed (endoscopy, neuronavigation, electrophysiological monitoring etc.), surgeon's estimate of tumour resection extent and presence of preoperative hydrocephalus.

\section{Postoperatively within one to four weeks from surgery}

Approximately one to two weeks post-operatively: neurological examination, postoperative speech and language status including speech and language recording or bedside assessment and medications used for treatment of CMS.

Approximately four weeks post-operatively: Development and treatment of postoperative intracranial haematoma and hydrocephalus, leakage of cerebrospinal fluid and need for ventilator. These complications are usually seen earlier but we wait until the fourth post-operative week to register these in order to ensure no complications are missed.

\section{Postoperatively two months after surgery}

Neurological examination, CMS-survey, speech and language recording or bedside assessment and any medications given to treat CMS since last registration.

\section{Postoperatively twelve months after surgery}

Neurological examination, speech and language status including speech and language recording or bedside assessment, medications given since last registration to treat CMS, chemo- and/or radiotherapy, neuropsychological assessment(s) if performed, final neuropathological classification of tumour, and additional neuroimaging performed since the first follow-up. Copies of the neuroimaging and descriptions performed pre- and postoperatively will be collected for central review.

\section{Acute and repeated neurosurgery}

In case of emergency surgery (e.g. due to risk of incarceration or coma) information about the study and invitation to participate can be given within seven days postoperatively. These patients will be included in all parts of the study except for the recording and analysis of preoperative speech and language status.

In cases with repeat tumour surgery during the twelve months follow-up, the patient can re-enter the study and start a new follow-up programme (Fig. 1, Repeated Surgeries). A new pre-operative registration is then performed corresponding to the re-operation. Post-operative registrations will be performed again, and used in the analysis of risk related to first versus further surgeries. If surgery is performed again after the twelve months follow-up period, the patient will be re-invited to participate in the study.

\section{Statistical considerations}

In accordance with our surgical hypothesis of $50 \%$ risk reduction by less traumatic techniques, and assuming that $35 \%$ of the patients are operated using an approach with a low risk of CMS (assumed to be 10\%) and the remaining $65 \%$ of patients are operated using other approaches (assumed carrying a 20\% risk), a total of 450 patients have to be included to identify a $5 \%$ significance level and $80 \%$ power. Based on a projected overall risk of CMS of $20 \%$, an estimated frequency of a specific SNP of 30\%, and a projected doubled risk of CMS with this particular SNP, we will need to include a total of 343 patients to identify such a genetic predisposition at a $5 \%$ significance level with $90 \%$ power.

\section{Discussion}

The study will be the largest prospective international study on CMS to date, and the first one to 1) systematically register surgery, use of steroids, standardized speech samples and 2) to investigate the influence of host genome. Detailed information on neuroradiological features, 


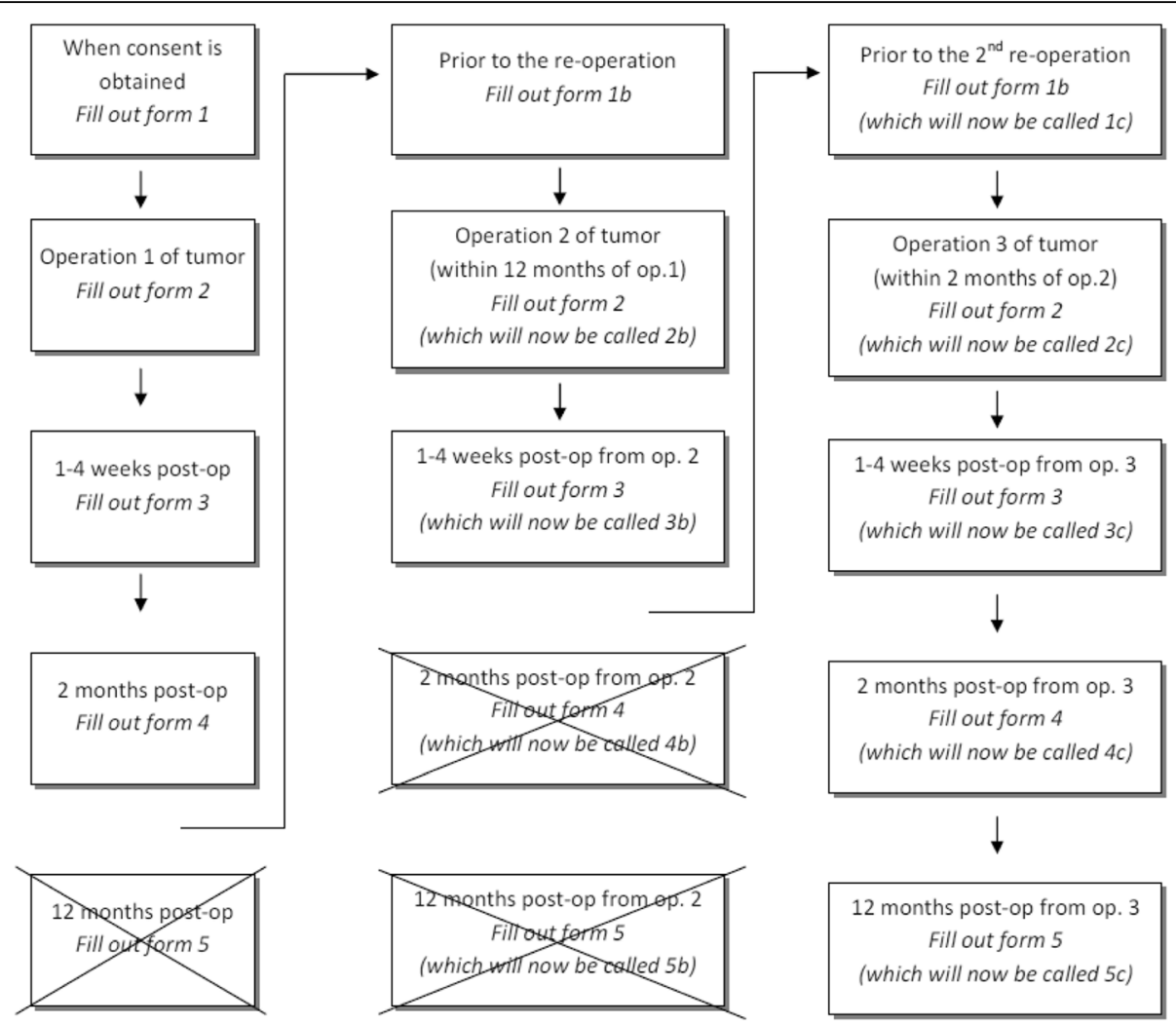

Fig. 1 The follow up process in case of repeated surgeries

tumour and patient characteristics (incl. Handedness and pre-language impairment) will also be gathered, and may help further elucidate the incidence and clinical course of the syndrome for various patient and tumour types.

On-line registration compliance rates to Nordic/Baltic multicentre trials are in general above 95\% [62]. Furthermore, we will implement an automated email reminder system at the four follow-up time points and the project coordinator and data manager will validate all data inputs, request clarifications and updates for unclear or missing data, and secure that DNA of sufficient quality is received, processed and stored for later host genome analyses.

Currently, a randomized intervention study is unrealistic due to limited data supporting any specific neurosurgical approach and given the diversity of tumour subtypes, localisation and invasiveness. However, such a randomisation may be realistic if the present study does not clearly identify surgical approaches with statistically significant reduced risks of CMS.

\section{Abbreviations}

CMS: Cerebellar mutism syndrome; CNS: Central nervous system; GWAS: Genomewide association studies (GWAS); SNP: Single nucleotide polymorphism

\section{Acknowledgements}

Peder Skov Wehner, and Steen Rosthøj (Denmark); Christoffer Ehrstedt, Peter Siesjö, Irene Devenney, Per Nyman, Magnus Sabel and Mattias Mattsson (Sweden); Einar Stensvold, Ingrid Torsvik and Tore Stokland (Norway); Mia
Westerholm-Ormio, Kristiina Nordfors, Jouni Pesola, Päivi Lähteenmäki and Satu Lehtinen (Finland); Rosita Kiudeliene and Giedre Rutkauskiene (Lithuania) have all recruited patients.

\section{Funding}

This study has received financial support from the Danish Children's Cancer Foundation, the Swedish Childhood Cancer Foundation the Dagmar Marshall foundation, The Danish Cancer Society and King Christian IX and Queen Louise's anniversary grant. The funding bodies have not had any role in designing the study, collecting, analysing or interpreting data, in writing the manuscript or in the decision to submit the manuscript for publication.

\section{Availability of data and materials}

Access to the protocol is possible through the corresponding author. All study information is registered in an online database. Access to the data is restricted to participating centres until the planned study is completed. The database may be opened for additional studies following completion of this ongoing study.

\section{Authors' contributions}

$\mathrm{TG}, \mathrm{AS}, \mathrm{KN}, \mathrm{KS}$, and MJ conceived the design of the study. TG performed literature research and drafted the primary protocol. MW subsequently made revisions, implemented the study and drafted the manuscript for this paper. $C C, N C, P G, M H, S H, T L, R M, O R$ and $H T$ contributed to the development of the pre- and postoperative registration forms except the neurosurgical registration form. JC, BG, AK and PN contributed to development of the neurosurgical registration form. CK contributed to the development of the strategies for neuroradiological analysis. RG contributed to the development of the strategies for genetic analysis. $1 \mathrm{O}$ contributed to the development of the neuropsychological test strategy, BZ and KP developed the strategies for speech analysis. All authors have revised and approved the final manuscript.

\section{Competing interests}

The authors declare that they have no competing interests. 


\section{Consent for publication}

Not applicable.

\section{Ethics approval and consent to participate}

The study has been approved by the Regional Ethics Committee for the Capital Region in Denmark (file H-6-2014-002), the Ethics Committee in Sweden (file 2014/3:8), Finland (file 176/13/03/03/2014) and Lithuania (file BE-2-29). The project is approved by the Danish Data Protection Agency (file 2007-58-0015). All participants give written informed consent to participate prior to enrolment in the study.

\section{Author details}

'Department of Neurosurgery, Rigshospitalet, Copenhagen, Denmark. ${ }^{2}$ Department of Pediatrics and Adolescent Medicine, Rigshospitalet, Copenhagen, Denmark. ${ }^{3}$ Department of Neurosurgery, St. Olavs Hospital, Trondheim, Norway. ${ }^{4}$ Department of Paediatrics Lund Skåne University Hospital, Lund, Sweden. ${ }^{5}$ Department of Pediatrics, Aarhus University Hospital, Skejby, Aarhus, Denmark. ${ }^{6}$ Department of Women's and Children's Health, Karolinska Universitetssjukhuset, Stockholm, Sweden. ${ }^{7}$ Posterior Fossa Society https://www.posteriorfossa.org. ${ }^{8}$ Department of Oncology and Palliation, North Zealand Hospital, Hillerød, Denmark. ${ }^{9}$ Center for Biological Sequence Analysis, Technical University of Denmark, Kgs. Lyngby, Denmark. ${ }^{10}$ Department of Neurosurgery, Karolinska University Hospital, Stockholm, Sweden. ${ }^{11}$ Department of Neurosurgery, Helsinki University Hospital, Helsinki, Finland. ${ }^{12}$ Department of Neuroradiology, University Hospital of Copenhagen, Rigshospitalet, Copenhagen, Denmark. ${ }^{13}$ Department of Child Neurology, Helsinki University Central Hospital, Helsinki, Finland.

${ }^{14}$ Department of Neuroscience, Neurosurgery, Akademiska sjukhuset, Uppsala, Sweden. ${ }^{15}$ Child and Youth Rehabilitation Centre, Habilitation and Technical Aid, Lund, Sweden. ${ }^{16}$ Institute of Clinical Medicine, University of Copenhagen, Copenhagen, Denmark. ${ }^{17}$ Division of Pediatric Hematology/ Oncology, Perlmutter Cancer Center, Univesity Langone Medical Center, New York, USA. ${ }^{18}$ Department of Pediatrics, St. Olavs Hospital, Trondheim, Norway. ${ }^{19}$ Department of Clinical Intervention and Technique, Karolinska Institute, Stockholm, Sweden

Received: 10 July 2016 Accepted: 9 June 2017

Published online: 21 June 2017

\section{References}

1. Rickert $\mathrm{CH}$, Paulus W. Epidemiology of central nervous system tumors in childhood and adolescence based on the new WHO classification. Childs Nerv Syst. 2001;17(9):503-11.

2. Sonderkaer S, Schmiegelow M, Carstensen H, Nielsen LB, Muller J, Schmiegelow K. Long-term neurological outcome of childhood brain tumors treated by surgery only. J Clin Oncol. 2003;21(7):1347-51.

3. Radcliffe J, Packer RJ, Atkins TE, Bunin GR, Schut L, Goldwein JW, et al. Threeand four-year cognitive outcome in children with noncortical brain tumors treated with whole-brain radiotherapy. Ann Neurol. 1992;32(4):551-4.

4. Ellenberg L, McComb JG, Siegel SE, Stowe S. Factors affecting intellectual outcome in pediatric brain tumor patients. Neurosurgery. 1987;21(5):638-44.

5. Livesey EA, Hindmarsh PC, Brook CG, Whitton AC, Bloom HJ, Tobias JS, et al. Endocrine disorders following treatment of childhood brain tumours. $\mathrm{Br} J$ Cancer. 1990;61(4):622-5.

6. Gunn ME, Lahdesmaki T, Malila N, Arola M, Gronroos M, Matomaki J, et al. Late morbidity in long-term survivors of childhood brain tumors: a nationwide registry-based study in Finland. Neuro-Oncology. 2014;

7. Gudrunardottir T, Sehested A, Juhler M, Schmiegelow K. Cerebellar mutism: review of the literature. Childs Nerv Syst. 2011;27(3):355-63.

8. Grill J, Viguier D, Kieffer V, Bulteau C, Sainte-Rose C, Hartmann O, et al. Critical risk factors for intellectual impairment in children with posterior fossa tumors: the role of cerebellar damage. J Neurosurg. 2004;101(2 Suppl):152-8.

9. Puget S, Boddaert N, Viguier D, Kieffer V, Bulteau C, Garnett M, et al. Injuries to inferior vermis and dentate nuclei predict poor neurological and neuropsychological outcome in children with malignant posterior fossa tumors. Cancer. 2009:115(6):1338-47.

10. Huber JF, Bradley K, Spiegler BJ, Dennis M. Long-term effects of transient cerebellar mutism after cerebellar astrocytoma or medulloblastoma tumor resection in childhood. Childs Nerv Syst. 2006;22(2):132-8.

11. Huber JF, Bradley K, Spiegler B, Dennis M. Long-term neuromotor speech deficits in survivors of childhood posterior fossa tumors: effects of tumor type, radiation, age at diagnosis, and survival years. J Child Neurol. 2007; 22(7):848-54.

12. Robertson PL, Muraszko KM, Holmes EJ, Sposto R, Packer RJ, Gajjar A, et al. Incidence and severity of postoperative cerebellar mutism syndrome in children with medulloblastoma: a prospective study by the Children's Oncology group. J Neurosurg. 2006;105(6 Suppl):444-51.

13. Gudrunardottir T, Sehested A, Juhler M, Grill J, Schmiegelow K. Cerebellar mutism: definitions, classification and grading of symptoms. Childs Nerv Syst. 2011;27(9):1361-3.

14. Gudrunardottir T, De Smet H, Bartha-Doering L, van Dun K, Verhoeven J, Paquier P, Mariën P: Posterior Fossa Syndrome (PFS) and Cerebellar Mutism. In: The linguistic cerebellum. edn. Edited by Mariën P, Manto M. Amsterdam: Academic Press; 2016: 257-313.

15. Van CF, Van de Laar A, Plets C, Goffin J, Casaer P. Transient cerebellar mutism after posterior fossa surgery in children. Neurosurgery. 1995;37(5):894-8.

16. Pollack IF, Polinko P, Albright AL, Towbin R, Fitz C. Mutism and pseudobulbar symptoms after resection of posterior fossa tumors in children: incidence and pathophysiology. Neurosurgery. 1995;37(5):885-93.

17. Kotil K, Eras M, Akcetin M, Bilge T. Cerebellar mutism following posterior fossa tumor resection in children. Turk Neurosurg. 2008;18(1):89-94.

18. Wells EM, Khademian ZP, Walsh KS, Vezina G, Sposto R, Keating RF, et al. Postoperative cerebellar mutism syndrome following treatment of medulloblastoma: neuroradiographic features and origin. J Neurosurg Pediatr. 2010;5(4):329-34

19. Catsman-Berrevoets CE, Aarsen FK. The spectrum of neurobehavioural deficits in the posterior fossa syndrome in children after cerebellar tumour surgery. Cortex. 2010;46(7):933-46.

20. Ersahin Y, Mutluer S, Cagli S, Duman Y. Cerebellar mutism: report of seven cases and review of the literature. Neurosurgery. 1996;38(1):60-5. discussion 66

21. Morris EB, Phillips NS, Laningham FH, Patay Z, Gajjar A, Wallace D, et al. Proximal dentatothalamocortical tract involvement in posterior fossa syndrome. Brain. 2009;132(Pt 11):3087-95.

22. van Baarsen KM, Grotenhuis JA. The anatomical substrate of cerebellar mutism. Med Hypotheses. 2014;82(6):774-80.

23. Wells EM, Walsh KS, Khademian ZP, Keating RF, Packer RJ. The cerebellar mutism syndrome and its relation to cerebellar cognitive function and the cerebellar cognitive affective disorder. Dev Disabil Res Rev. 2008;14(3):221-8.

24. Law N, Greenberg M, Bouffet E, Taylor MD, Laughlin S, Strother D, et al. Clinical and neuroanatomical predictors of cerebellar mutism syndrome. Neuro-Oncology. 2012;14(10):1294-303.

25. Schmahmann JD, Sherman JC. The cerebellar cognitive affective syndrome. Brain. 1998;121(Pt 4):561-79.

26. Stoodley CJ, Schmahmann JD. Functional topography in the human cerebellum: a meta-analysis of neuroimaging studies. Neurolmage. 2009; 44(2):489-501.

27. Stoodley CJ, Schmahmann JD. Evidence for topographic organization in the cerebellum of motor control versus cognitive and affective processing. Cortex. 2010;46(7):831-44.

28. Baillieux H, De Smet HJ, Paquier PF, De Deyn PP, Marien P. Cerebellar neurocognition: insights into the bottom of the brain. Clin Neurol Neurosurg. 2008;110(8):763-73.

29. Marien P, Engelborghs S, Fabbro F, De Deyn PP. The lateralized linguistic cerebellum: a review and a new hypothesis. Brain Lang. 2001;79(3):580-600.

30. Miller NG, Reddick WE, Kocak M, Glass JO, Lobel U, Morris B, et al. Cerebellocerebral diaschisis is the likely mechanism of postsurgical posterio fossa syndrome in pediatric patients with midline cerebellar tumors. AJNR Am J Neuroradiol. 2010;31(2):288-94.

31. De Smet HJ, Baillieux H, Wackenier P, De Praeter M, Engelborghs S, Paquier $P F$, et al. Long-term cognitive deficits following posterior fossa tumor resection: a neuropsychological and functional neuroimaging follow-up study. Neuropsychology. 2009;23(6):694-704.

32. Doxey D, Bruce D, Sklar F, Swift D, Shapiro K. Posterior fossa syndrome: identifiable risk factors and irreversible complications. Pediatr Neurosurg. 1999:31(3):131-6.

33. Korah MP, Esiashvili N, Mazewski CM, Hudgins RJ, Tighiouart M, Janss AJ, et al. Incidence, risks, and sequelae of posterior fossa syndrome in pediatric medulloblastoma. Int J Radiat Oncol Biol Phys. 2010;77(1):106-12.

34. Catsman-Berrevoets CE, Van Dongen HR, Mulder PG, Geuze D, Paquier PF, Lequin $\mathrm{MH}$. Tumour type and size are high risk factors for the syndrome of "cerebellar" mutism and subsequent dysarthria. J Neurol Neurosurg Psychiatry. 1999;67(6):755-7. 
35. Reed-Berendt R, Phillips B, Picton S, Chumas P, Warren D, Livingston JH, et al. Cause and outcome of cerebellar mutism: evidence from a systematic review. Childs Nerv Syst. 2014;30(3):375-85.

36. McMillan HJ, Keene DL, Matzinger MA, Vassilyadi M, Nzau M, Ventureyra EC. Brainstem compression: a predictor of postoperative cerebellar mutism. Childs Nerv Syst. 2009;25(6):677-81.

37. Di RC, Chieffo D, Frassanito P, Caldarelli M, Massimi L, Tamburrini G. Heralding cerebellar mutism: evidence for pre-surgical language impairment as primary risk factor in posterior fossa surgery. Cerebellum. 2011;10(3):551-62.

38. Kupeli S, Yalcin B, Bilginer B, Akalan N, Haksal P, Buyukpamukcu M. Posterior fossa syndrome after posterior fossa surgery in children with brain tumors. Pediatr Blood Cancer. 2011;56(2):206-10.

39. Zaheer SN, Wood M. Experiences with the telovelar approach to fourth ventricular tumors in children. Pediatr Neurosurg. 2010;46(5):340-3.

40. Avula S, Mallucci C, Kumar R, Pizer B. Posterior fossa syndrome following brain tumour resection: review of pathophysiology and a new hypothesis on its pathogenesis. Childs Nerv Syst. 2015;31(10):1859-67.

41. Gelabert-Gonzalez M, Fernandez-Villa J. Mutism after posterior fossa surgery. Review of the literature. Clin Neurol Neurosurg. 2001;103(2):111-4.

42. Pollack IF. Posterior fossa syndrome. Int Rev Neurobiol. 1997:41:411-32.

43. Zhou W, Xu D, Peng X, Zhang Q, Jia J, Crutcher KA. Meta-analysis of APOE4 allele and outcome after traumatic brain injury. J Neurotrauma. 2008;25(4): 279-90.

44. Dardiotis E, Fountas KN, Dardioti M, Xiromerisiou G, Kapsalaki E, Tasiou A, et al. Genetic association studies in patients with traumatic brain injury. Neurosurg Focus. 2010;28(1):E9.

45. Waters RJ, Nicoll JA. Genetic influences on outcome following acute neurological insults. Curr Opin Crit Care. 2005;11(2):105-10.

46. Caner H, Altinors N, Benli S, Calisaneller T, Albayrak A. Akinetic mutism after fourth ventricle choroid plexus papilloma: treatment with a dopamine agonist. Surg Neurol. 1999;51(2):181-4.

47. Shyu C, Burke K, Souweidane MM, Dunkel IJ, Gilheeney SW, Gershon T, et al. Novel use of zolpidem in cerebellar mutism syndrome. J Pediatr Hematol Oncol. 2011:33(2):148-9.

48. Akhaddar A, Salami M, El Asri AC, Boucetta M. Treatment of postoperative cerebellar mutism with fluoxetine. Childs Nerv Syst. 2012;28(4):507-8.

49. Pitsika M, Tsitouras V. Cerebellar mutism. J Neurosurg Pediatr. 2013;12(6):604-14.

50. Kuper M, Timmann D. Cerebellar mutism. Brain Lang. 2013;127(3):327-33.

51. Hockey B, Leslie K, Williams D. Dexamethasone for intracranial neurosurgery and anaesthesia. J Clin Neurosci. 2009;16(11):1389-93.

52. Mekitarian FE, Carvalho WB, Cavalheiro S, Horigoshi NK, Freddi NA, Vieira GK. Hyperglycemia and postoperative outcomes in pediatric neurosurgery. Clinics (Sao Paulo). 2011;66(9):1637-40.

53. Wesolowska A, Dalgaard MD, Borst L, Gautier L, Bak M, Weinhold N, et al. Cost-effective multiplexing before capture allows screening of 25000 clinically relevant SNPs in childhood acute lymphoblastic leukemia. Leukemia. 2011;25(6):1001-6.

54. Wesolowska-Andersen A, Borst L, Dalgaard MD, Yadav R, Rasmussen KK, Wehner PS, et al. Genomic profiling of thousands of candidate polymorphisms predicts risk of relapse in 778 Danish and German childhood acute lymphoblastic leukemia patients. Leukemia. 2014;

55. Edwards $P$, Arango M, Balica L, Cottingham R, El-Sayed H, Farrell B, et al. Final results of MRC CRASH, a randomised placebo-controlled trial of intravenous corticosteroid in adults with head injury-outcomes at 6 months. Lancet. 2005:365(9475):1957-9.

56. Roberts I, Yates D, Sandercock P, Farrell B, Wasserberg J, Lomas G, et al. Effect of intravenous corticosteroids on death within 14 days in 10008 adults with clinically significant head injury (MRC CRASH trial): randomised placebo-controlled trial. Lancet. 2004;364(9442):1321-8.

57. Taylor MD, Northcott PA, Korshunov A, Remke M, Cho YJ, Clifford SC, et al. Molecular subgroups of medulloblastoma: the current consensus. Acta Neuropathol. 2012;123(4):465-72.

58. Perreault S, Ramaswamy V, Achrol AS, Chao K, Liu TT, Shih D, et al. MRI surrogates for molecular subgroups of medulloblastoma. AJNR Am J Neuroradiol. 2014;35(7):1263-9.

59. Raybaud C, Ramaswamy V, Taylor MD, Laughlin S. Posterior fossa tumors in children: developmental anatomy and diagnostic imaging. Childs Nerv Syst. 2015;31(10):1661-76

60. Patay Z. Postoperative posterior fossa syndrome: unraveling the etiology and underlying pathophysiology by using magnetic resonance imaging Childs Nerv Syst. 2015;31(10):1853-8.
61. Spiteri M, Windridge $D$, Avula $S$, Kumar R, Lewis E. Identifying quantitative imaging features of posterior fossa syndrome in longitudinal MRI. J Med Imag. 2015;2:044502.

62. Frandsen TL, Heyman M, Abrahamsson J, Vettenranta K, Asberg A Vaitkeviciene $\mathrm{G}$, et al. Complying with the European clinical trials directive while surviving the administrative pressure - an alternative approach to toxicity registration in a cancer trial. Eur J Cancer. 2014;50(2):251-9.

\section{Submit your next manuscript to BioMed Central and we will help you at every step:}

- We accept pre-submission inquiries

- Our selector tool helps you to find the most relevant journal

- We provide round the clock customer support

- Convenient online submission

- Thorough peer review

- Inclusion in PubMed and all major indexing services

- Maximum visibility for your research

Submit your manuscript at www.biomedcentral.com/submit
) Biomed Central 